\title{
How Much Progress Have We Made? Trends in Disparities in Tobacco Use
}

\author{
J.H. Kingsbury, $\mathrm{PhD}^{1}$; J. D’Silva, PhD, MPH${ }^{2}$; E. O’Gara, PhD²; M.J. Parks, PhD ${ }^{1}$; R.G. Boyle, PhD ${ }^{3}$
}

Accessible Version: www.cdc.gov/pcd/issues/2020/20_0090.htm

Suggested citation for this article: Kingsbury JH, D'Silva J,

O'Gara E, Parks MJ, Boyle RG. How Much Progress Have We

Made? Trends in Disparities in Tobacco Use. Prev Chronic Dis 2020;17:200090. DOI: https://doi.org/10.5888/pcd17.200090.

\section{PEER REVIEWED}

\section{Summary}

What is already known on this topic?

Recent evidence has shown that disparities in cigarette use across demographic groups remain unchanged or have worsened.

What is added by this report?

Our study replicates these findings for cigarettes and reveals a similar pattern for other tobacco products whereby disparities in use of e-cigarettes, cigars, and smokeless tobacco have not changed in the past 8 years, even in a state with comprehensive smoke-free laws and high tobacco taxes.

What are the implications for public health practice?

Tobacco control professionals and policy makers must prioritize equity with any proposed strategies or policies to reduce persistent disparities and achieve tobacco-free societies.

\section{Abstract}

\section{Introduction}

Reducing tobacco-related health disparities has been a public health priority for more than 2 decades, yet disparities in cigarette use have remained steady or worsened. Less is known about how disparities in other tobacco products have changed over time. Our study examined trends in cigarette and other tobacco product use in Minnesota with the goal of informing efforts aimed at reducing disparities.

\section{Methods}

We examined tobacco use disparities as a function of education, income, and race across the Minnesota Adult Tobacco Survey results in $2010(\mathrm{~N}=7,057), 2014(\mathrm{~N}=9,304)$, and $2018(\mathrm{~N}=6,055)$. Tobacco use was captured by assessing past 30-day use of 4 to- bacco products: cigarettes, cigars, e-cigarettes, and smokeless tobacco, plus combustibles (ie, cigarettes and/or cigars) and any tobacco (ie, use of any of the 4 products).

\section{Results}

At each wave, those with lower income and education reported greater use of cigarettes, combustibles, and any tobacco than those with higher income and education. Black respondents were more likely to report cigar and combustibles use than White respondents in 2018, whereas White respondents were more likely to report smokeless tobacco use in 2014 . We saw no significant waveby-demographic interactions, suggesting that the magnitude of the disparity remained unchanged over time for any tobacco product.

\section{Conclusion}

Substantial disparities in tobacco use remain across education, income, and race, even in a state such as Minnesota with a strong tobacco control program. Additional efforts are needed to close disparity gaps and reach endgame tobacco use targets for all subpopulations.

\section{Introduction}

Although cigarette smoking has decreased substantially in the United States over the past several decades (1), declines in prevalence have been slower for some communities (2). Smoking disparities remain unchanged $(3,4)$ or have increased $(5,6)$ for several groups who are targeted by the tobacco industry. Many racial and ethnic minority groups smoke at higher rates than the national average $(4,7)$, as do people who identify as belonging to sexual and gender minority groups (7) and those with lower socioeconomic status $(8,9)$. At the same time, some subpopulations are at or approaching endgame levels of cigarette use $(<5 \%)$. For example, only $4.1 \%$ of those with a graduate degree report current cigarette use compared with $23.1 \%$ of those with less than a high school diploma (1). Further efforts are needed to achieve low smoking prevalence across all subpopulations.

Cigarettes remain both the most deadly and commonly used commercial tobacco product (1); however, many other products (eg, e- 
cigarettes, cigars) have gained in popularity $(10,11)$, and less is known about disparities in use of these products. Promotion by the tobacco industry (10) has successfully led to increases in the use of some tobacco products. For instance, e-cigarette use has increased dramatically among youth and young adults in the past 5 to 8 years $(1,12)$, and the use of cigars has grown in the past $2 \mathrm{dec}$ ades among non-Hispanic Black adults (13). Understanding whether trends are changing across all tobacco products is an increasingly important issue given that current tobacco control efforts have reported little success in reducing tobacco use disparities overall (3-6). Furthermore, if groups that experience tobaccorelated disparities (eg, low income/education, racial/ethnic minorities) continue to use combustible products while those with high incomes and education and White smokers quit or switch to less harmful products, disparities in tobacco-related health outcomes could be exacerbated.

Although reducing disparities has been a public health priority for more than 2 decades (14) and some promising frameworks have been identified (eg, the social determinants of health approach) (8), more work is needed to elucidate effective approaches for reducing tobacco-related disparities at the state and national level. Examining tobacco use data from states with strong tobacco control programs may help inform efforts to reduce tobacco-related disparities, because these locations may offer an environment that is more conducive to equitable progress in tobacco control.

Our study examines trends in cigarette and other tobacco product use to measure progress in reducing tobacco-related disparities. This is especially relevant in Minnesota, a US state with comprehensive and long-term tobacco control programs. For more than 2 decades, Minnesota has taken actions to address tobacco use through banning indoor smoking, increasing tobacco taxes, providing free cessation services, and implementing other normchange initiatives - efforts that have helped decrease adult smoking prevalence by 35\% since 1999 and youth smoking prevalence by $70 \%$ since 2000 (15). Despite these efforts, previous research has identified gaps in the effectiveness of changing statewide cigarette smoking rates across all communities (6). We sought to provide estimates of other tobacco product use and examine changes in use over time by using data from 3 rounds of the Minnesota Adult Tobacco Survey (MATS) (16).

\section{Methods}

Data. We used data from the 2010, 2014, and 2018 MATS, a statewide, cross-sectional telephone survey that assessed tobacco use among Minnesotans aged 18 or older $(2010, \mathrm{~N}=7,057 ; 2014$, 9,304; and 2018, 6,055). The survey used a landline and cellular telephone random-digit-dial sampling method. Sampling con- sisted of a 2-step process: a household screening questionnaire to identify households, followed by sampling within the household. Combined response rates ranged from $71 \%$ to $73 \%$ across the 3 waves. Data were weighted to account for sampling and geographic stratification, ensuring statewide representativeness. Additional information on MATS is available elsewhere (16). This study was approved by the Minnesota Department of Health Institutional Review Board.

Sample. We examined overall prevalence and differences by education and income for the entire study sample at each wave. Analyses examining race were limited to respondents who selfreported race as Black/African American or White.

Measures. Tobacco use was measured as use in the past 30 days of 4 tobacco products: cigarettes, cigars, e-cigarettes, or smokeless tobacco. Respondents reporting that they had used a particular product at least once in the past 30 days were categorized as users of that product. Combustible tobacco users were those reporting any past use in the past 30 days of cigarettes, cigars, or both; any tobacco users were those reporting use of any of the 4 tobacco products in the past 30 days.

Tobacco use disparities were examined as a function of education, income, and race. Education and household income were transformed into categorical variables $(0=$ high school diploma, general equivalency diploma, or less [low education]; $1=$ some college or more [medium/high education] $)$ and low income $(0=\leq \$ 25,000$ / y) versus medium/high income $(1=>\$ 25,000 / y)$. Those with low income and/or education historically reported higher tobacco use than those with medium/high income and education, so we were particularly interested in examining use in these groups. Race was assessed via a single question with 6 response options (White, Black, Asian, Native Hawaiian/Pacific Islander, American Indian/ Alaskan Native, other). Analyses examining racial disparities focused on White and Black respondents because of sample size.

Analysis. Weighted prevalence for each tobacco product and category of use (combustible, any use) was calculated at each wave for the entire sample, low versus medium/high education, low versus medium/high income, and Black versus White race. We used weighted logistic regression to test for demographic differences at each wave. These analyses used dummy variables for education, income, Black or White race, and survey wave. The reference group for the survey wave variable was alternated to test for differences over time (ie, 2010-2014, 2014-2018, 2010-2018). An interaction term (ie, demographic-by-survey wave) was used to determine whether differences in each demographic variable changed over the 3 waves. All analyses were conducted in SPSS version 24 (IBM Corp).

The opinions expressed by authors contributing to this journal do not necessarily reflect the opinions of the U.S. Department of Health and Human Services, the Public Health Service, the Centers for Disease Control and Prevention, or the authors' affiliated institutions. 


\section{Results}

Cigarettes were the most commonly used tobacco product at each wave $(17.3 \%$ in $2010,15.5 \%$ in 2014 , and $15.3 \%$ in 2018$)$, followed by smokeless tobacco in $2010(4.0 \%)$ and by e-cigarettes in $2014(5.9 \%)$ and $2018(6.0 \%)$ ( Table).

\section{Changes in use over time}

Logistic regression analyses showed a significant decrease in cigarette use from 2010 through 2014 (odds ratio [OR] $=0.88 ; 95 \%$ CI, 0.78-0.98) and from 2010 through 2018 (OR $=0.87 ; 95 \%$ CI, 0.76-0.99). Combustible product use decreased significantly from 2010 to 2014 (OR $=0.88 ; 95 \%$ CI, 0.79-0.99), and a significant increase occurred in e-cigarette use from 2010 to $2014(\mathrm{OR}=$ 8.97; 95\% CI, 5.59-14.37) and between 2010 and 2018 (OR = 9.06; 95\% CI, 5.60-14.68). All other comparisons were nonsignificant.

\section{Changes in demographic characteristics within wave}

Income. Respondents with low income reported higher prevalence at each wave than those with medium/high income (ORs $=2.18$ in $2010,1.90$ in 2014, 2.42 in 2018). There were no differences in cigar use by income at any wave. Respondents with low income reported more e-cigarette use in 2014 (OR $=1.43$; 95\% CI, 1.04-1.97), and those with low income reported less smokeless tobacco use in $2018(\mathrm{OR}=0.36 ; 95 \% \mathrm{CI}, 0.16-0.77)$. Those with low income also reported more use of combustible tobacco $(\mathrm{OR}=$ $2.00 ; 95 \% \mathrm{CI}, 1.78-2.16)$ and any tobacco $(\mathrm{ORs}=1.73$ in 2010 , 1.62 in $2014,1.79$ in 2018) than did those with medium/high income at all waves.

Education. Similar patterns were observed for education. Those with low education reported more cigarette use than those with medium/high education at each wave $(\mathrm{ORs}=1.53$ in $2010,1.97$ in $2014,2.11$ in 2018). A similar use pattern was observed for cigars in $2010(\mathrm{OR}=1.51 ; 95 \% \mathrm{CI}, 1.01-2.25)$, e-cigarettes at all waves $(\mathrm{OR}=2.77$ in 2010, 1.42 in 2014, 1.79 in 2018) and for smokeless tobacco in 2014 (OR $=1.66$; 95\% CI, 1.21-2.29). Those with low education reported more use of combustibles (ORs $=1.47$ in $2010 ; 1.80$ in $2014 ; 1.97$ in 2018) and any tobacco use $(\mathrm{OR}=1.48$ in $2010,1.74$ in $2014,1.97$ in 2018) at all waves.

Race. We found no significant differences in the use of cigarettes, e-cigarettes, or any tobacco product between Black and White respondents at any wave. Black respondents were significantly more likely to report cigar use than White respondents in 2018 (OR = 2.42; 95\% CI, 1.08-5.39). White respondents were more likely than Black respondents to report smokeless tobacco use in 2014 $(\mathrm{OR}=0.09 ; 95 \% \mathrm{CI}, 0.02-0.39)$, and Black respondents were more likely than White respondents to report combustible tobacco use in $2018(\mathrm{OR}=1.62 ; 95 \% \mathrm{CI}, 1.07-2.47)$.

\section{Wave-by-demographic interactions}

We used logistic regression to test for changes in demographic differences over time. We found no significant wave-bydemographic interactions (wave-by-income, wave-by-education, wave-by-race) for any tobacco product or product category.

\section{Discussion}

Data from statewide surveys in 2010, 2014, and 2018 showed no change in disparities by race, education, or income for the use of cigarettes or other tobacco products. These findings are consistent with previous research demonstrating that disparities in cigarette use have remained largely unchanged since $2002(3,4)$ and extend the literature by demonstrating that this pattern is present for other tobacco products (ie, cigars, smokeless tobacco, e-cigarettes) and product categories (ie, combustibles, any tobacco), particularly in a state with comprehensive and long-term tobacco control programs. Because several counties set targets at very low levels of cigarette smoking, our findings highlight 2 key needs: 1) addressing tobacco use other than cigarettes, and 2) devoting more focus to population subgroups that are disproportionately affected by tobacco-related disparities. Additional efforts should go beyond policies that have been effective at reducing overall smoking, and instead use a tailored approach to target other tobacco products and disparately affected communities.

Cigarettes remain the most commonly used tobacco product among adults (1). Consistent with this finding, many tobacco control initiatives are aimed at reducing cigarette use. Our findings highlight the need for future tobacco control initiatives and media campaigns to target other tobacco products (eg, e-cigarettes) $(10,11)$ as patterns of use shift.

Trend analyses indicated that overall cigarette use in Minnesota decreased from 2010 to 2014 but not from 2014 to 2018. These findings differ from national data, which indicate a significant decline over this time period (17). The stalled smoking rate may be due in part to decreases in quit attempts and quit success among smokers in Minnesota (16) and possibly the fading impact of a tobacco excise tax increase from 2013.

Some researchers have employed modeling to identify promising approaches to reducing tobacco-related disparities. For example, a recent study by Combs and colleagues (18) found that many pointof-sale policies (eg, restricting sales of menthol or all cigarettes to

The opinions expressed by authors contributing to this journal do not necessarily reflect the opinions of the U.S. Department of Health and Human Services, the Public Health Service, the Centers for Disease Control and Prevention, or the authors' affiliated institutions. 
tobacco specialty shops) would have the smallest impact on low income and Black populations because these groups are more likely to live in areas with a high density of tobacco retailers. Combining restrictions on menthol cigarette sales with a 2,000foot retailer-to-retailer buffer would produce a more equitable effect. Golden and colleagues (19) tested the effect of minimum price laws and excise taxes on socioeconomic disparities in smoking. Their models projected that minimum price laws would reduce disparities more than comparable excise taxes (eg, a $\$ 2.00$ increase in minimum price vs a $\$ 2.00$ increase in excise tax). These models offer important insights but are most valuable when considered in conjunction with real-world policy evaluations.

Literature reviews may also help identify promising policy approaches for reducing tobacco-related disparities. For example, Brown and colleagues found that price and tax increases had a consistent, positive impact on socioeconomic inequities for adults (20) and youth (21); other policies and interventions had a neutral or negative equity impact. Additional reviews examining equity impact by race, education, geography, sexual orientation, and gender identity are needed to inform the development of proequity tobacco control policies.

As many populations move toward very low levels of cigarette smoking, some have advocated for advancing from conventional tobacco control efforts to more aggressive endgame strategies. These hypothetical endgame approaches, such as ending the sale of commercial tobacco (22), have the potential to improve public health broadly and increase equity in communities that are disproportionately affected by tobacco. However, some approaches, while good-intentioned, may have unintended consequences. For example, if the United States moved to reduce the nicotine content in cigarettes to minimally addictive levels but cigars were excluded from nicotine reduction, this may have the unintended effect of exacerbating disparities for Black versus White tobacco users. Moreover, a cigarette-only policy would not address disparities in the use of other tobacco products. To achieve societies that are completely free of commercial tobacco, tobacco control professionals and policy makers must prioritize equity with any proposed strategies and policy initiatives (8).

Ten years after passage of the Family Smoking Prevention and Tobacco Control Act (23), the Food and Drug Administration has yet to exercise its full authority to regulate tobacco products. State- and local-level regulatory efforts will likely be needed for more advanced tobacco policies, such as density policies and those that restrict the sale of flavored (eg, menthol, fruit, candy) tobacco products (24). The best opportunity for advancing equity may be a combination of local, state, and federal actions.
Our study had limitations. The study employed a past-30-day use measure to ensure uniform measurement across tobacco products over time. Use of additional measures that assess current use frequency (eg, every day, some days) would facilitate comparisons with national data (2) and should be employed in future studies. The current study focused on a single US state and may have limited generalizability to other states or countries. The design of MATS limited our examination of racial disparities to $2 \mathrm{racial} / \mathrm{eth}-$ nic groups. Robust studies examining how tobacco use disparities are changing over time for other racial/ethnic groups would strengthen the literature. The current study did not examine changes in hookah use; future research should assess this emerging product. Research should also consider heterogeneity within racial/ethnic subgroups (eg, African American race, Somali or Oromo ethnicity). In addition, MATS is conducted every 4 years, so is less able to document rapid changes in use patterns. More frequent assessments are recommended for future research to evaluate progress in reducing tobacco-related disparities.

Substantial disparities in cigarette and other tobacco product use remain across education, income, and race, even in a state with a strong tobacco control program. Novel approaches are needed at the state and local levels to address use of multiple forms of tobacco and to close disparity gaps and reach endgame tobacco use targets for all subpopulations.

\section{Acknowledgments}

We thank Paula Keller and Ann St. Claire for reviewing an earlier draft of this article. This research was funded by ClearWay Minnesota, an independent nonprofit organization, and State Core Tobacco Control funding from the Centers for Disease Control and Prevention (CDC) CDC-RFA-DP15-1509 (1U58DP006005-01). The survey firm, Westat Inc., we used for data collection was through a contract with ClearWay Minnesota. CDC had no role in the study design, data collection, analysis, interpretation of data, writing of the article, or decision to submit for publication. The authors declare no conflicts of interest. No copyrighted materials were used in this article.

\section{Author Information}

Corresponding Author: John Kingsbury, PhD, Minnesota Department of Health, 85 7th Place East, St. Paul, MN 55101. Telephone: 651-201-3663. Email: john.kingsbury@state.mn.us.

Author Affiliations: ${ }^{1}$ Minnesota Department of Health, St. Paul, Minnesota. ${ }^{2}$ ClearWay Minnesota, Bloomington, Minnesota. ${ }^{3}$ University of California, Office of the President, Oakland, California.

The opinions expressed by authors contributing to this journal do not necessarily reflect the opinions of the U.S. Department of Health and Human Services, the Public Health Service, the Centers for Disease Control and Prevention, or the authors' affiliated institutions. 


\section{References}

1. Wang TW, Asman K, Gentzke AS, Cullen KA, Holder-Hayes E, Reyes-Guzman C, et al. Tobacco product use among adults — United States, 2017. MMWR Morb Mortal Wkly Rep 2018; 67(44):1225-32.

2. Creamer MR, Wang TW, Babb S, Cullen KA, Day H, Willis $\mathrm{G}$, et al. Tobacco product use and cessation indicators among adults — United States, 2018. MMWR Morb Mortal Wkly Rep 2019;68(45):1013-9.

3. Martell BN, Garrett BE, Caraballo RS. Disparities in adult cigarette smoking - United States, 2002-2005 and 2010-2013. MMWR Morb Mortal Wkly Rep 2016; 65(30):753-8.

4. U.S. Department of Health and Human Services. The health consequences of smoking - 50 years of progress: a report of the Surgeon General. Atlanta (GA): US Department of Health and Human Services, Centers for Disease Control and Prevention, National Center for Chronic Disease Prevention and Health Promotion, Office on Smoking and Health; 2014.

5. Agaku IT, Odani S, Okuyemi KS, Armour B. Disparities in current cigarette smoking among US adults, 2002-2016. Tob Control 2020;29(3):269-76.

6. Boyle RG, D'Silva J, Stanton CA, Carusi C, Tang Z. Disparities in cigarette smoking and use of other tobacco products in Minnesota, 2003-14. J Public Health (Oxf) 2018; 40(2):E74-E81. . Erratum in J Public Health (Oxf) 2017; 39(4):881.

7. Jamal A, Phillips E, Gentzke AS, Homa DM, Babb SD, King BA, et al. Current cigarette smoking among adults - United States, 2016. MMWR Morb Mortal Wkly Rep 2018; 67(2):53-9.

8. Garrett BE, Dube SR, Babb S, McAfee T. Addressing the social determinants of health to reduce tobacco-related disparities. Nicotine Tob Res 2015;17(8):892-7.

9. Garrett BE, Martell BN, Caraballo RS, King BA. Socioeconomic differences in cigarette smoking among sociodemographic groups. Prev Chronic Dis 2019;16:E74.

10. Kasza KA, Ambrose BK, Conway KP, Borek N, Taylor K, Goniewicz ML, et al. Tobacco-product use by adults and youths in the United States in 2013 and 2014. N Engl J Med 2017;376(4):342-53.

11. Gammon DG, Rogers T, Coats EM, Nonnemaker JM, Marynak KL, Kuiper NM, et al. National and state patterns of concept-flavoured cigar sales, USA, 2012-2016. Tob Control 2019;28(4):394-400.
12. Gentzke AS, Creamer M, Cullen KA, Ambrose BK, Willis G, Jamal A, et al. Vital signs: tobacco product use among middle and high school students - United States, 2011-2018. MMWR Morb Mortal Wkly Rep 2019;68(6):157-64.

13. Rostron BL, Corey CG, Gindi RM. Cigar smoking prevalence and morbidity among US adults, 2000-2015. Prev Med Rep 2019; $14: 100821$.

14. US Department of Health and Human Services. Tobacco use among US racial/ethnic minority groups - African Americans, American Indians and Alaska Natives, Asian Americans and Pacific Islanders, and Hispanics: a report of the Surgeon General. Atlanta (GA): US Department of Health and Human Services, Centers for Disease Control and Prevention, National Center for Chronic Disease Prevention and Health Promotion, Office on Smoking and Health; 1998.

15. ClearWay Minnesota. ClearWay Minnesota commemorates 20 years of reducing tobacco's harm. 2019; http:// clearwaymn.org/clearway-minnesota-commemorates-20-yearsof-reducing-tobaccos-harm/. Accessed May 9, 2020.

16. ClearWay Minnesota, Minnesota Department of Health. Minnesota Adult Tobacco Survey. 2018 ; http:// clearwaymn.org/mats/. Accessed May 9, 2020.

17. National Center for Health Statistics. National Health Interview Survey. https://www.cdc.gov/nchs/nhis/index.htm. Accessed May 9, 2020.

18. Combs TB, McKay VR, Ornstein J, Mahoney M, Cork K, Brosi D, et al. Modelling the impact of menthol sales restrictions and retailer density reduction policies: insights from tobacco town Minnesota. Tob Control 2019; tobaccocontrol-2019-054986.

19. Golden SD, Farrelly MC, Luke DA, Ribisl KM. Comparing projected impacts of cigarette floor price and excise tax policies on socioeconomic disparities in smoking. Tob Control 2016;25(Suppl 1):i60-6.

20. Brown T, Platt S, Amos A. Equity impact of population-level interventions and policies to reduce smoking in adults: a systematic review. Drug Alcohol Depend 2014;138:7-16.

21. Brown T, Platt S, Amos A. Equity impact of interventions and policies to reduce smoking in youth: systematic review. Tob Control 2014;23(e2):e98-105.

22. Smith EA, Malone RE. An argument for phasing out sales of cigarettes. Tob Control 2019; tobaccocontrol-2019-055079.

23. US Department of Agriculture, Food and Drug Administration. Family Smoking Prevention and Tobacco Control Act - an overview. https://www.fda.gov/tobacco-products/rulesregulations-and-guidance/family-smoking-prevention-andtobacco-control-act-overview. Accessed July 2, 2020.

The opinions expressed by authors contributing to this journal do not necessarily reflect the opinions of the U.S. Department of Health and Human Services, the Public Health Service, the Centers for Disease Control and Prevention, or the authors' affiliated institutions. 
24. Truth Initiative. A decade of the Tobacco Control Act. Where are we now? June 27, 2019. https://truthinitiative.org/researchresources/tobacco-prevention-efforts/decade-tobacco-controlact-where-are-we-now. Accessed December 1, 2019. 


\section{Table}

Table. Prevalence of Tobacco Use Over Past 30 Days by Demographic Characteristics Across Survey Wave, Minnesota Adult Tobacco Survey (MATS) ${ }^{a}$

\begin{tabular}{|c|c|c|c|}
\hline Characteristic & $2010(N=7,057)$ & $2014(N=9,304)$ & $2018(N=6,055)$ \\
\hline \multicolumn{4}{|c|}{ Cigarettes } \\
\hline Overall & $17.3(16.1-18.5)$ & $15.5(14.5-16.5)$ & $15.3(14.1-16.6)$ \\
\hline \multicolumn{4}{|l|}{ Race } \\
\hline Black & $26.7(18.3-37.1)$ & $23.3(17.2-30.7)$ & $23.2(16.9-31.1)$ \\
\hline White & $16.5(15.3-17.8)$ & $14.9(13.8-16.0)$ & $14.7(13.4-16.1)$ \\
\hline \multicolumn{4}{|l|}{ Annual income, $\$^{b}$} \\
\hline$\leq 25,000$ & $30.0(26.4-33.8)$ & $26.6(23.6-29.9)$ & $30.4(25.9-35.2)$ \\
\hline$>25,000$ & $14.8(13.6-16.2)$ & $13.7(12.5-14.9)$ & $12.7(11.4-14.1)$ \\
\hline \multicolumn{4}{|l|}{ Education $^{c}$} \\
\hline$\leq$ High school diploma or GED & $23.1(20.7-25.7)$ & $22.4(20.3-24.6)$ & $23.3(20.6-26.3)$ \\
\hline$\geq$ Some college & $14.0(12.8-15.4)$ & $11.9(10.9-13.1)$ & $11.5(10.3-12.9)$ \\
\hline \multicolumn{4}{|c|}{ Cigars } \\
\hline Overall & $3.2(2.7-3.9)$ & $2.9(2.5-3.5)$ & $3.0(2.4-3.7)$ \\
\hline \multicolumn{4}{|l|}{ Race } \\
\hline Black & $6.9(3.0-14.8)$ & $5.8(3.0-10.9)$ & $7.0(3.7-13.1)$ \\
\hline White & $3.2(2.7-3.9)$ & $2.8(2.3-3.3)$ & $2.8(2.2-3.5)$ \\
\hline \multicolumn{4}{|l|}{ Annual income, $\mathbf{\$}^{\mathrm{b}}$} \\
\hline$\leq 25,000$ & $4.0(2.6-6.1)$ & $3.1(2.1-4.7)$ & $4.7(2.9-7.6)$ \\
\hline$>25,000$ & $3.3(2.7-4.0)$ & $3.0(2.5-3.6)$ & $2.7(2.1-3.4)$ \\
\hline \multicolumn{4}{|l|}{ Education $^{c}$} \\
\hline$\leq$ High school diploma or GED & $4.0(2.9-5.3)$ & $3.0(2.2-4.0)$ & $4.2(2.9-5.9)$ \\
\hline$\geq$ Some college & $2.9(2.3-3.5)$ & $2.9(2.4-3.6)$ & $2.4(1.9-3.0)$ \\
\hline \multicolumn{4}{|c|}{ E-Cigarettes } \\
\hline Overall & $0.7(0.4-1.1)$ & $5.9(5.3-6.7)$ & $6.0(5.2-6.9)$ \\
\hline \multicolumn{4}{|l|}{ Race } \\
\hline Black & $1.4(0.2-9.2)$ & $5.3(2.7-10.3)$ & $5.1(2.4-10.4)$ \\
\hline White & $0.7(0.4-1.0)$ & $5.8(5.1-6.5)$ & $5.8(4.9-6.8)$ \\
\hline \multicolumn{4}{|l|}{ Annual income, $\$^{b}$} \\
\hline$\leq 25,000$ & $1.4(0.7-3.1)$ & $8.5(6.7-10.8)$ & $8.5(6.2-11.4)$ \\
\hline$>25,000$ & $0.5(0.3-0.9)$ & $5.5(4.8-6.4)$ & $5.3(4.4-6.3)$ \\
\hline \multicolumn{4}{|l|}{ Education $^{c}$} \\
\hline$\leq$ High school diploma or GED & $1.3(0.7-2.4)$ & $7.6(6.3-9.1)$ & $8.2(6.5-10.4)$ \\
\hline zSome college & $0.4(0.2-0.7)$ & $5.1(4.4-5.9)$ & $4.8(4.0-5.8)$ \\
\hline
\end{tabular}

Abbreviation: GED, general equivalency diploma.

${ }^{a}$ Values are percentage $(95 \% \mathrm{Cl})$. Estimates represent tobacco use over the past 30 days and thus may differ from previously reported current tobacco use estimates from MATS (16).

${ }^{b}$ Low income ( $\left.\leq \$ 25,000\right)$; medium or high income $(>\$ 25,000)$.

${ }^{\mathrm{c}}$ Low education (high school diploma, general equivalency diploma, or less); high education (some college or more).

(continued on next page)

The opinions expressed by authors contributing to this journal do not necessarily reflect the opinions of the U.S. Department of Health and Human Services, the Public Health Service, the Centers for Disease Control and Prevention, or the authors' affiliated institutions. 
(continued)

Table. Prevalence of Tobacco Use Over Past 30 Days by Demographic Characteristics Across Survey Wave, Minnesota Adult Tobacco Survey (MATS) ${ }^{a}$

\begin{tabular}{|c|c|c|c|}
\hline Characteristic & $2010(N=7,057)$ & $2014(N=9,304)$ & $2018(N=6,055)$ \\
\hline \multicolumn{4}{|c|}{ Smokeless Tobacco } \\
\hline Overall & $4.0(3.4-4.7)$ & $3.6(3.1-4.1)$ & $3.2(2.6-3.8)$ \\
\hline \multicolumn{4}{|l|}{ Race } \\
\hline Black & $1.0(0.2-4.9)$ & $0.4(0.1-1.5)$ & $0.9(0.2-3.7)$ \\
\hline White & $4.2(3.5-4.9)$ & $3.9(3.4-4.5)$ & $3.6(3.0-4.4)$ \\
\hline \multicolumn{4}{|l|}{ Annual income, $\$$ b } \\
\hline$\leq 25,000$ & $3.6(2.3-5.5)$ & $3.5(2.4-5.1)$ & $1.5(0.8-3.1)$ \\
\hline$>25,000$ & $4.3(3.6-5.1)$ & $3.8(3.3-4.5)$ & $3.7(3.0-4.6)$ \\
\hline \multicolumn{4}{|l|}{ Education $^{c}$} \\
\hline sHigh school diploma or GED & $4.7(3.6-6.2)$ & $4.5(3.6-5.7)$ & $3.6(2.6-5.1)$ \\
\hline$\geq$ Some college & $3.6(3.0-4.4)$ & $3.1(2.6-3.7)$ & $3.0(2.4-3.7)$ \\
\hline \multicolumn{4}{|c|}{ Combustible Tobacco (Cigarettes and/or Cigars) } \\
\hline Overall & $18.8(17.5-20.0)$ & $16.9(15.9-18.0)$ & $16.9(15.6-18.3)$ \\
\hline \multicolumn{4}{|l|}{ Race } \\
\hline Black & $28.2(19.6-38.8)$ & $25.1(18.8-32.6)$ & $26.7(20.0-34.7)$ \\
\hline White & $18.1(16.9-19.4)$ & $16.4(15.3-17.5)$ & $16.4(15.0-17.9)$ \\
\hline \multicolumn{4}{|l|}{ Annual income, $\$^{b}$} \\
\hline$\leq 25,000$ & $30.7(27.1-34.6)$ & $27.6(24.5-30.9)$ & $31.3(26.6-35.9)$ \\
\hline$>25,000$ & $16.6(15.3-18.1)$ & $15.4(14.2-16.6)$ & $14.6(13.3-16.1)$ \\
\hline \multicolumn{4}{|l|}{ Education $^{\mathrm{c}}$} \\
\hline sHigh school diploma or GED & $24.2(21.8-26.8)$ & $23.4(21.3-25.7)$ & $24.8(22.0-27.8)$ \\
\hline$\geq$ Some college & $15.7(14.4-17.1)$ & $13.7(12.6-14.9)$ & $13.3(12.0-14.7)$ \\
\hline \multicolumn{4}{|c|}{ Any Tobacco } \\
\hline Overall & $21.2(19.8-22.4)$ & $20.5(19.4-21.7)$ & $21.4(20.0-22.9)$ \\
\hline \multicolumn{4}{|l|}{ Race } \\
\hline Black & $28.4(19.8-39.0)$ & $27.6(21.1-35.2)$ & $27.4(20.7-35.4)$ \\
\hline White & $20.6(19.3-21.9)$ & $20.1(18.9-21.3)$ & $20.9(19.4-22.5)$ \\
\hline \multicolumn{4}{|l|}{ Annual income, $\$^{b}$} \\
\hline$\leq 25,000$ & $31.7(28.1-35.6)$ & $31.3(27.9-34.4)$ & $34.4(29.9-39.3)$ \\
\hline$>25,000$ & $19.4(18.0-20.9)$ & $19.2(17.9-20.5)$ & $19.4(17.8-21.0)$ \\
\hline \multicolumn{4}{|l|}{ Education $^{c}$} \\
\hline sHigh school diploma or GED & $26.7(24.2-29.4)$ & $27.4(25.2-29.8)$ & $29.9(26.9-33.0)$ \\
\hline >Some college & $18.0(16.6-19.4)$ & $17.1(15.9-18.4)$ & $17.3(15.8-18.9)$ \\
\hline
\end{tabular}

Abbreviation: GED, general equivalency diploma.

${ }^{a}$ Values are percentage $(95 \% \mathrm{Cl})$. Estimates represent tobacco use over the past 30 days and thus may differ from previously reported current tobacco use estimates from MATS (16).

${ }^{\mathrm{b}}$ Low income $(\leq \$ 25,000)$; medium or high income $(>\$ 25,000)$.

${ }^{c}$ Low education (high school diploma, general equivalency diploma, or less); high education (some college or more).

The opinions expressed by authors contributing to this journal do not necessarily reflect the opinions of the U.S. Department of Health and Human Services, the Public Health Service, the Centers for Disease Control and Prevention, or the authors' affiliated institutions. 